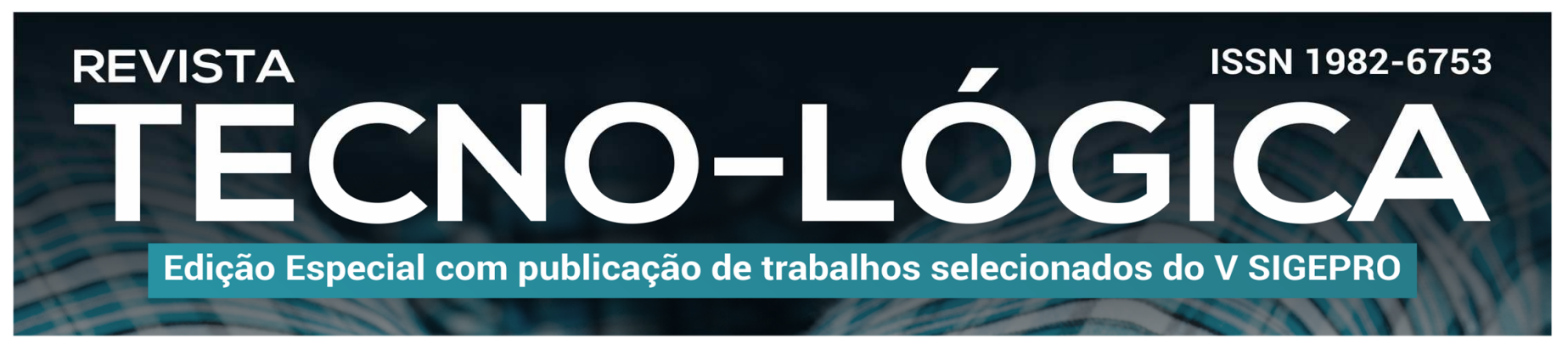

\title{
PRODUÇÃO DE FACE SHIELDS UTILIZANDO A MANUFATURA ADITIVA: UM AUXÍLIO PARA O COMBATE AO COVID-19
}

\author{
Fabiano Alberto Rosal, Gabriel Leites Souza ${ }^{1}$, José Lucas de Lourenssi Oliveiral, Vitor Sales Dias da Rosal \\ IInstituto Federal de Santa Catarina, 89503550, Caçador, Brasil.
}

E-mail: gabriel.ls2000@aluno.ifsc.edu.br

Recebido em:17/09/2020 Aceito em: 06/11/2020 DOI: 10.17058/tecnolog.v2i0.15758

\section{RESUMO}

Com a crise epidemiológica enfrentada nesse momento pela população brasileira, faz-se necessário utilizar as IES (instituições de Ensino Superior), que possuem conhecimentos acumulados para auxiliar no combate ao Covid-19. O IFSC, por meio de suas práticas de extensão e com a infraestrutura e equipamentos disponíveis no campus, é possível ofertar à comunidade itens de primeira necessidade médica e auxiliá-la. Nesse contexto, foi desenvolvido um projeto utilizando a manufatura aditiva para a produção de Face Shields. Em vista disso, o projeto buscou empregar a tecnologia de impressão 3D para planejar e fabricar protetores faciais. Utilizou-se como base um modelo já existente no mercado e, a partir disso, foram realizadas algumas alterações buscando otimizar o processo e reduzir custos de fabricação. Ao final, os protetores foram doados aos profissionais de saúde do município de Caçador-SC para auxiliá-los no combate ao Covid-19.

Palavras-chave: Manufatura aditiva. Impressão 3D. Planejamento do Produto. Modelagem.

\section{Introdução}

$\mathrm{Na}$ atualidade, as indústrias buscam inovações tecnológicas com o propósito de alcançar uma manufatura com grau superior de agilidade e versatilidade aos processos já existentes, concebendo produtos com geometrias complexas. Deste modo, emerge a Manufatura Aditiva, que é um processo produtivo que vem se destacando cada vez mais nas empresas que a empregam. Segundo Monzón et al. [1] a Manufatura Aditiva (MA), consiste na criação de objetos tridimensionais por deposição de material em camadas, através de movimentação computadorizada [1]. Ela é utilizada tanto para criação de protótipos, bem como para produção em massa e compõe as tecnologias que constroem projetos em 3D.

Uma das principais técnicas de manufatura aditiva, a impressão tridimensional (3D) vem sendo amplamente empregada. A tecnologia mais utilizada é a de FDM (Fusion and Deposition Modeling), que se baseia no fatiamento de uma imagem em 3D, e que segue o método de deposição de materiais por meio de um filamento, este, extrudado através de um bico que controla a taxa de extrusão e resolução para a concepção dos modelos [2]. Este sistema de produção reduz os desperdícios, pois 


\section{REVISTA}

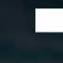

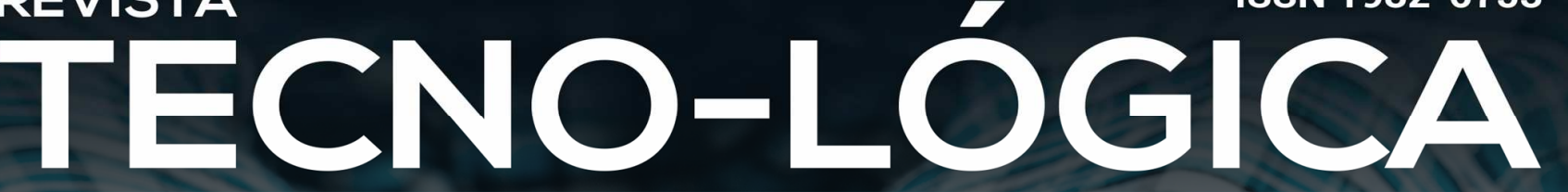

Edição Especial com publicação de trabalhos selecionados do V SIGEPRO

o objeto já estará no formato desejado apresentando um ótimo aproveitamento da matéria prima.

A impressora 3D se demonstra como um instrumento que propicia a adaptação a cenários inéditos que não foram planejados, devido ao alto grau de customização e a possibilidade de desenvolver produtos inovadores [3]. O presente trabalho tem o intuito de realizar um estudo acerca da tecnologia de impressão 3D para assim realizar a produção de máscaras protetoras (Face Shields), relacionando, dessa forma, os eixos de ensino, pesquisa e extensão.

Recentemente, surgiu o COVID-19, que segundo a OMS (Organização Mundial da Saúde), é uma doença infecciosa causada pela corona vírus, identificado pela primeira vez em dezembro de 2019, em Wuhan, na China. Também, se sabe que em humanos, ele causa infecções respiratórias que variam do resfriado comum a doenças mais graves. Tal panorama acarretou em uma crise mundial sem precedentes, devido ao elevado número de pacientes diagnosticados com a doença ocasionando uma necessidade de se utilizar equipamentos de proteção individual (EPI's) por parte da população, em especial os profissionais da saúde que estão na linha de frente no combate à doença, com o intuito de evitar a contaminação. Em vista disso, foi desenvolvido um projeto de extensão, cuja finalidade foi produzir e doar máscaras protetoras (Face Shields) projetadas utilizando como referência um modelo pré-existente no mercado, buscando otimizar os recursos e o processo de fabricação, com o intuito de auxiliar os profissionais de saúde do município de Caçador-SC no combate ao Covid - 19.

\section{Objetivos}

TECNO-LÓGICA, Santa Cruz do Sul, v. 24, n. nesp, p. 334-341, jul./dez. 2020
O objetivo geral do projeto é realizar a produção de máscaras protetoras (Face Shields) através da impressora 3D e entregá-las aos profissionais de saúde do município de CaçadorSC. Dentro do objetivo geral, existem quatro objetivos específicos: a) Reunir informações relevantes acerca das características do processo de impressão 3D; b) Projetar e imprimir as máscaras utilizando como referência um modelo pré-existente no mercado; c) Realizar a higienização e montagem dos componentes; d) Efetuar a entrega aos profissionais de saúde e afins.

\section{Referencial Teórico}

\subsection{Impressão $3 D$}

A impressão 3D é um conjunto de tecnologias de manufatura aditiva e consiste na criação de objetos tridimensionais por deposição de material em camadas através de movimentação computadorizada. Gibson et al. definiram oito etapas comumente necessárias na produção utilizando manufatura aditiva, sendo elas [4]:

-Modelagem CAD (Computer-aided design): As peças produzidas a partir da manufatura aditiva devem ter sua geometria externa definida utilizando um software. Pode ser empregado na maioria dos softwares profissionais de CAD ou sistemas e equipamentos de engenharia reversa, como scanners a laser, por exemplo;

- Conversão para STL (Surface Tessellation Language): Por ser o formato padrão da indústria, é aceito na maioria dos equipamentos de manufatura aditiva;

-Transferência para a máquina de manufatura aditiva e manipulação do arquivo: Deve ocorrer a transferência do arquivo STL que representa a peça para o equipamento em que será

A matéria publicada nesse periódico é licenciada sob forma de uma Licença Creative Commons - Atribuição 4.0 Internacional http://creativecommons.org/licenses/by/4.0/

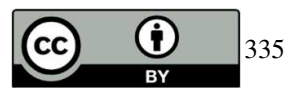




\section{REVISTA}

r

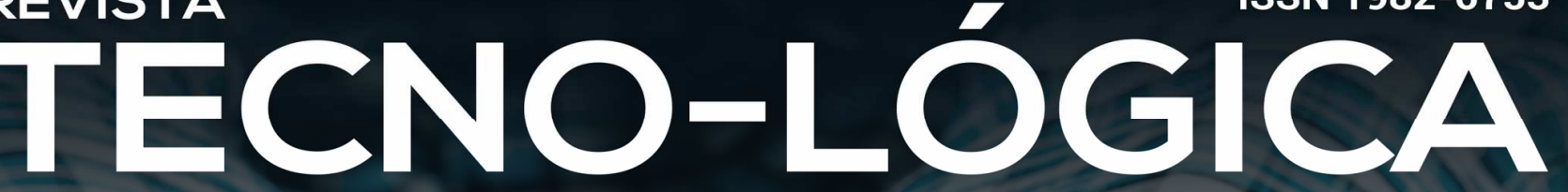

Edição Especial com publicação de trabalhos selecionados do V SIGEPRO

produzido a peça. Podem ocorrer eventuais manipulações para corrigir o posicionamento, tamanho ou orientação da peça;

- Configurar a máquina: Eventualmente, se faz necessário definir alguns parâmetros na máquina, como tempo de produção, espessura de camada etc.;

- Produção: Por ser um processo automatizado, a manufatura aditiva não exige a supervisão por parte de um operador, porém é recomendável que se realize a checagem ao decorrer do processo para garantir que não haverá falta de material ou para atuar em eventuais problemas;

-Remoção: Após o término do processo, faz-se necessário a remoção da peça na máquina;

-Pós-Processamento: Depois de ser produzida, a peça pode passar por atividades adicionais como por exemplo, a retirada de estruturas de suporte, limpeza e tratamentos adicionais para garantir qualidades estéticas à peça, como pintura e tratamentos de superfícies, buscando assim características físicas desejadas, como resistência e dureza;

- Aplicação: A peça está finalizada e pronta para utilização.

\subsection{Aplicação da impressão $3 D$}

A produção de itens utilizando a manufatura aditiva ainda está fortemente ligada a projetos de baixo volume, alta grau de customização e alto valor, mesmo assim ela se mostra como uma técnica com grande potencial de fabricação de produtos de elevadas taxas de complexidade e variedade de mix de produção. Além disso, dentro do processo de manufatura aditiva, há uma grande variação de tecnologias que apresentam diversas características em termos de material utilizado, custo, investimento etc. Assim, possibilitando uma maior variabilidade de escolha ao se fabricar um produto buscando técnicas que se ajustem às características do produto a ser fabricado [5].

\subsection{Modelagem por Deposição de Material Fundido (FDM)}

$\mathrm{Na}$ técnica de modelagem por deposição de material fundido as peças são feitas através da extrusão de filamentos de resinas termoplásticas como o ABS ou o PLA, em que os filamentos são aquecidos a altas temperaturas por um cabeçote onde são fundidos e extrudados. O cabeçote se movimenta nas coordenadas $\mathrm{X}$ e $\mathrm{Y}$, já a plataforma se movimenta no sentido vertical (coordenada Z). O cabeçote está ligado a um bico extrusor aquecido que recebe o material por ele e é depositado na plataforma de construção distribuindo o material de acordo com a geometria desejada da peça. Pode-se utilizar outro bico auxiliar para depositar material. Ao término da deposição de cada camada, a plataforma se desloca para baixo (coordenada Z), com distância igual à espessura de camada, compondo, assim, camadas superpostas de filamento até formar o objeto pretendido.

Em alguns equipamentos, o processo ocorre todo no interior de uma câmara com temperatura controlada, abaixo da temperatura de transição vítrea da resina, permitindo um maior controle do processo [6]. A técnica FDM, é altamente recomendada, devido ao seu baixo custo [3].

\section{Metodologia}

A metodologia deu-se pela sequência dos passos abaixo:

\subsection{Agregar informações}




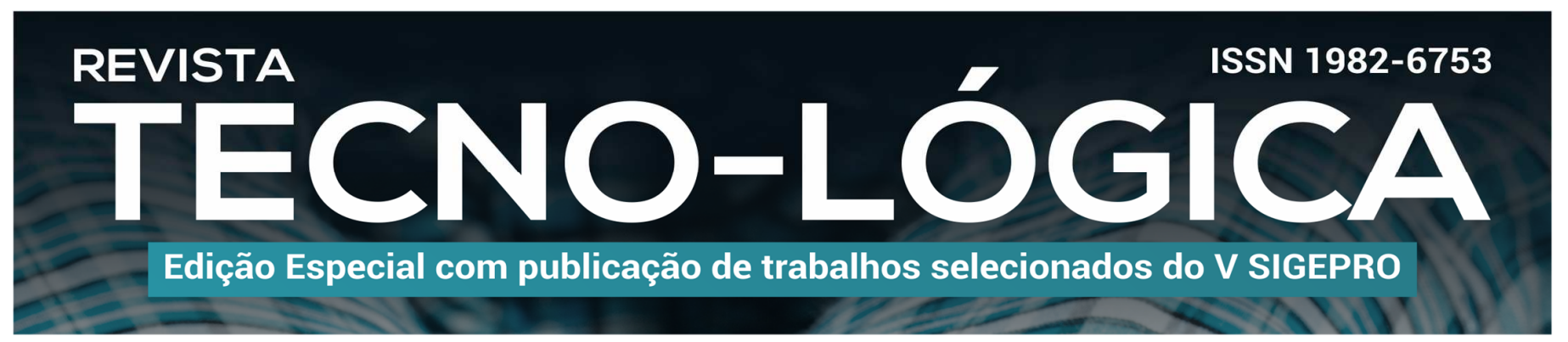

Inicialmente, realizou-se uma pesquisa bibliográfica para obter informações relevantes a respeito da utilização da impressora 3D, com o objetivo de entender as principais características dos seus processos, a fim de adquirir uma base teórica para posterior início de produção das máscaras faciais.

\subsection{Pesquisa de exemplares de máscaras protetoras}

Realizou-se um estudo dos exemplares de máscaras protetoras já desenvolvidas, com o intuito de se ter um suporte para a implementação e aperfeiçoamento das mesmas.

O modelo escolhido foi o RC1, elaborado e disponibilizado na internet pela empresa Prusa Research com sede em Praga, na República Tcheca. O RC1 permite que se ajuste mais peças em uma única mesa de impressão, aumentando assim a eficiência de produção. Além deste, a Prusa também liberou um item para a parte inferior da máscara, conforme segue na figura 1.

A
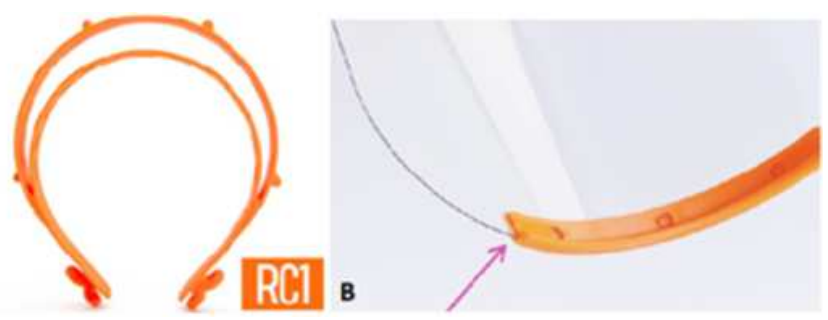

Figura 1 - A) Versões RC1 e RC2 e B) Componente para parte inferior (Adaptado Prusa Research (2020) [7])

\subsection{Elaboração do modelo CAD}

Baseando-se no modelo RC1, desenvolveu-se um desenho no software SolidWorks, apresentado na figura 2. Alguns ajustes foram realizados com o objetivo de maximizar a eficiência da impressora 3D, como:
A) A espessura da peça foi reduzida, minimizando o tempo de impressão e o uso de filamento;

B) Ocorreu uma adaptação dos pinos de fixação por meio da implantação de uma circunferência na ponta, de modo que a folha de acetato transparente fixasse melhor;

C) Efetuou-se uma alteração na parte traseira que sustenta a máscara na cabeça para que se adequasse a um elástico de prender dinheiro.

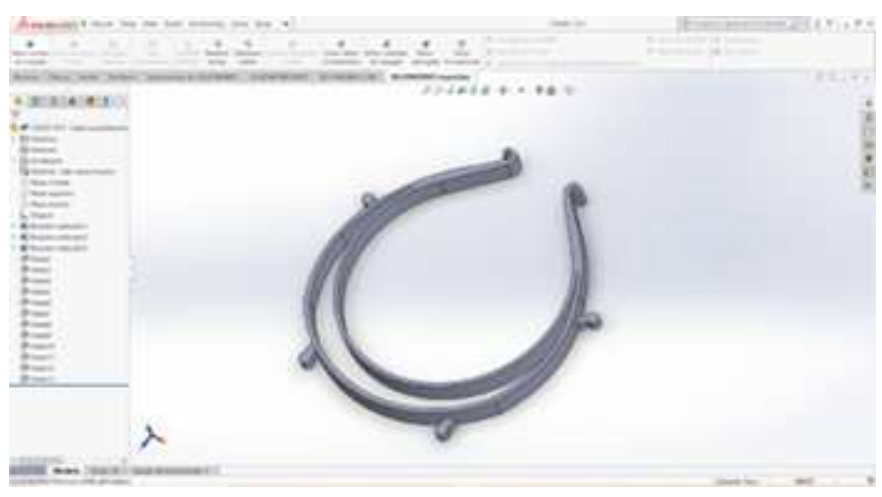

Figura 2- Desenho do modelo elaborado (SolidWorks)

\subsection{Conversão de arquivo}

Converteu-se para o formato STL, por ser o formato padrão da indústria, e é aceito na maioria dos equipamentos de manufatura aditiva, esse formato separa um arquivo tridimensional em partes imensamente menores. Utilizou-se o software Simplify3D, que viabiliza a modificação de diversos parâmetros de impressão, como: Altura de camada, ajuste de temperatura, velocidade de impressão, entre outros, como visto na figura 3. 


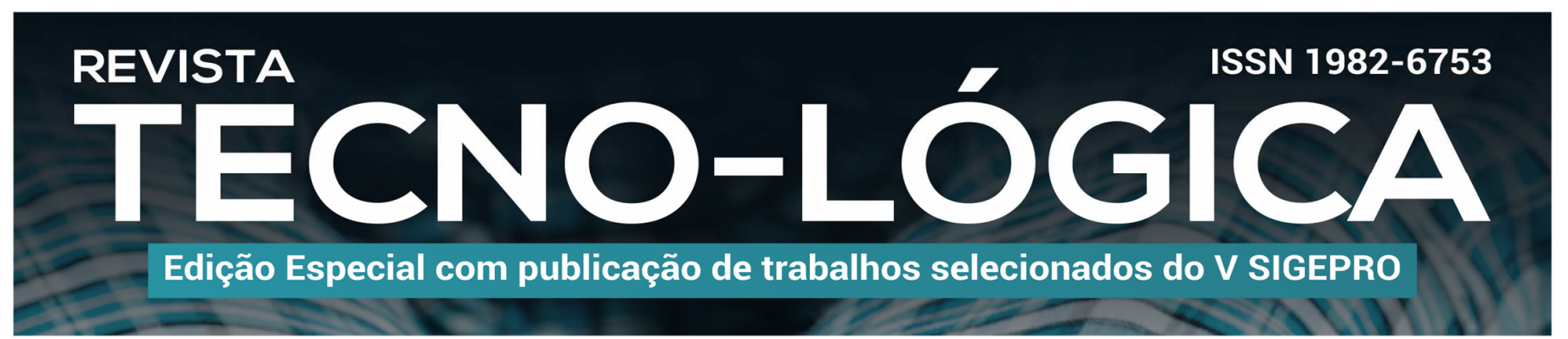

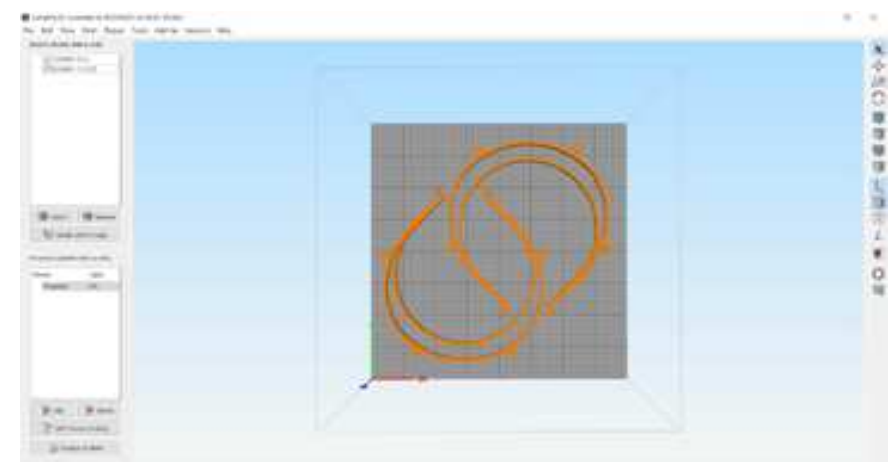

Figura 3 - Arquivo convertido em formato STL (Simplify3D)

\subsection{Produção dos componentes}

$\mathrm{O}$ arquivo STL foi transferido à impressora 3D via cartão SD. Foi utilizada a impressora Sethi 3D, modelo S2 de arquitetura fechada, conforme ilustra a figura 4.

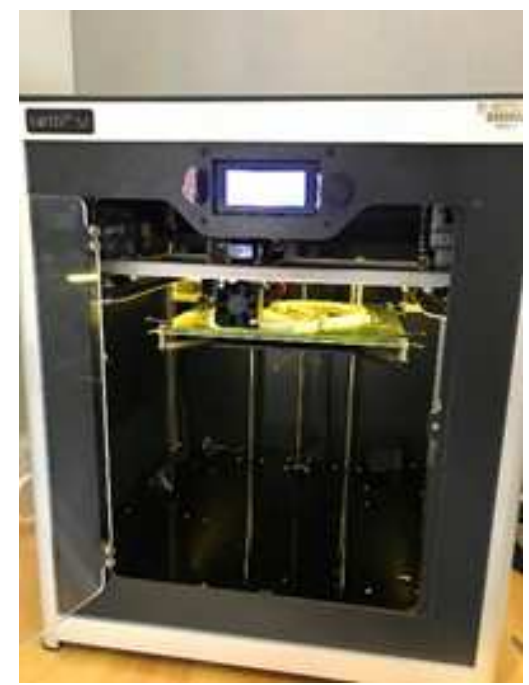

Figura 4 - Impressora 3D (modelo Sethi 3D S2)

Com base nos parâmetros da tabela 1 , foram fabricadas as máscaras faciais para análise dos resultados dos protótipos e diagnóstico de possíveis melhorias para produção em larga escala.
Foi utilizado o ABS (Acrilonitrila butadieno estireno) como matéria prima para realizar a impressão, este que é um polímero oriundo do petróleo e extremamente empregado nas indústrias devido às suas características de flexibilidade, alta resistência mecânica, facilidade de operação e acabamento.

Tabela 1 - Principais parâmetros de fabricação

\begin{tabular}{cc}
\hline Parâmetros & Valores \\
\hline Material & ABS \\
Temperatura da extrusora & $235^{\circ} \mathrm{C}$ \\
Temperatura da mesa & $110^{\circ} \mathrm{C}$ \\
Altura das camadas & $0,4 \mathrm{~mm}$ \\
\hline
\end{tabular}

\subsection{Viseiras}

Foram utilizadas folhas de acetato (formato A4) para encaixar nas partes superior e inferior produzidas na impressora e para servir como viseira protetora das máscaras. Então, realizouse a furação delas utilizando um perfurador para o encaixe final. A opção pela utilização das folhas decorreu-se por apresentar um ótimo custo e benefício, não prejudicar a visão dos usuários, e ser eficiente na proteção de respingos de pacientes.

\subsection{Esterilização e montagem das Faces Shields}

As viseiras foram levadas ao laboratório de química do IFSC - Instituto Federal de Santa Catarina, Campus Caçador, que foi o local utilizado e mais adequado para o processo de higienização. Para evitar a contaminação das peças fabricadas, realizou-se a higienização das mesmas, e os integrantes do projeto utilizaram máscaras N95, luvas descartáveis, além da correta higienização de mãos e braços antes dos EPI's serem tocados.

A matéria publicada nesse periódico é licenciada sob forma de uma Licença Creative Commons - Atribuição 4.0 Internacional http://creativecommons.org/licenses/by/4.0/

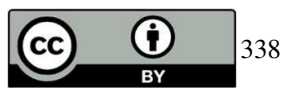




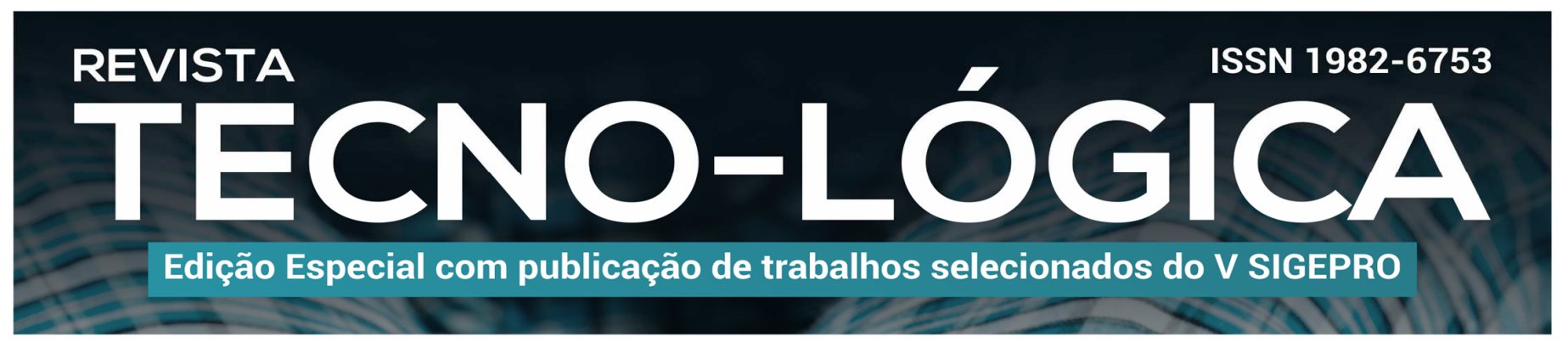

Após vestir os EPIs, foi feita a higienização das bancadas com álcool $70 \%$ líquido e cobriu-as com papel toalha.

As peças foram mergulhadas dentro de uma bacia em uma solução de $200 \mathrm{ml}$ de hipoclorito de sódio (água sanitária) e 5 litros de água, sem adição de perfumes. Elas foram deixadas de molho por 10 minutos até a retirada, conforme segue na figura 5 .

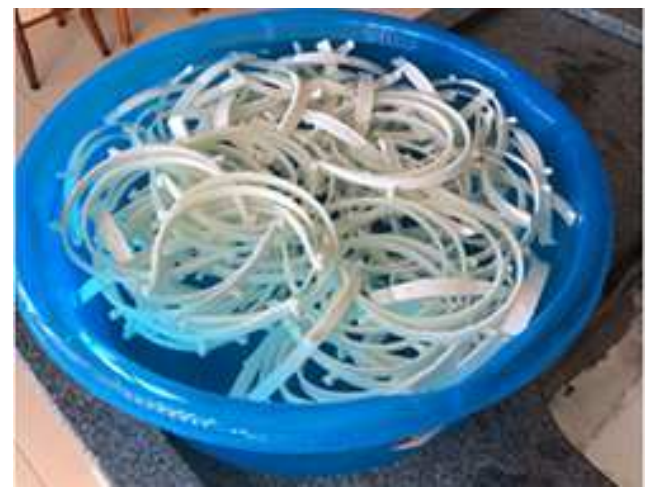

Figura 5 - Peças mergulhadas na solução

Após a secagem, realizou-se a montagem dos protetores faciais, como pode ser visualizado na figura 6. Os componentes utilizados foram:

1. Parte superior - faixa para a cabeça;

2. Parte inferior - queixo;

3. Faixa elástica;

4. Folha de acetato.

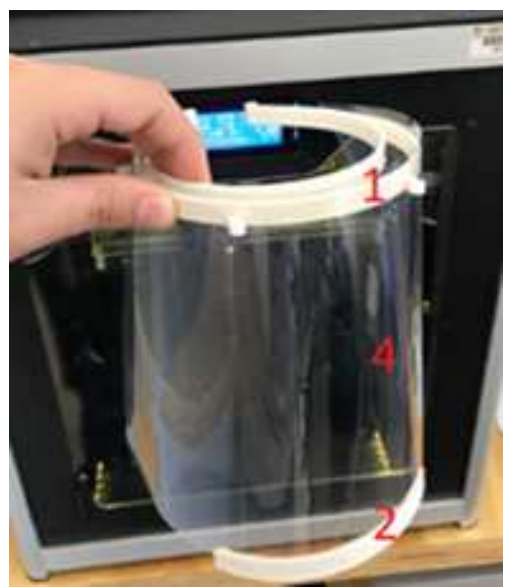

Figura 6 - Protetor facial com todos os componentes

Em seguida, encaixou-se a folha de acetato perfurada na parte superior, bem como na parte inferior do escudo. Posteriormente, posicionou-se o elástico nas bordas da máscara, como segue na figura 7. Por fim, as máscaras foram embaladas e armazenadas em caixas organizadoras para o ato de entrega.

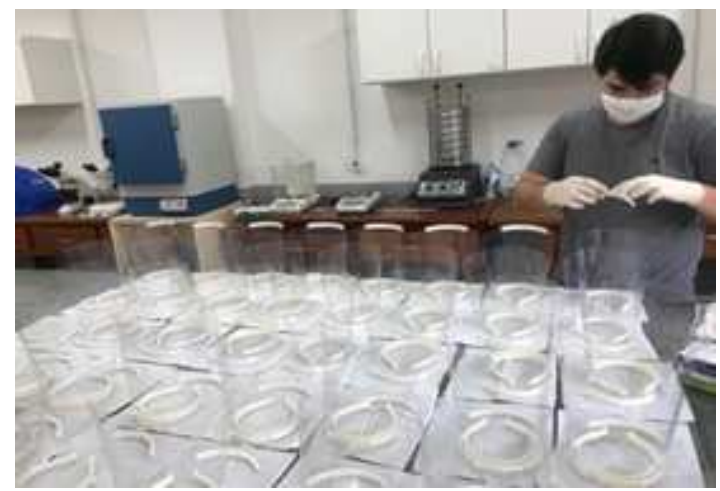

Figura 7 - Integrante realizando a montagem dos protetores faciais

\subsection{Doações das máscaras}

Entre os meses de abril e junho, foram doados ao todo 543 protetores faciais conforme segue a figura 8 , dentre elas, 28 foram para o Hospital Maicé, 15 ao Corpo de Bombeiros, 10 ao

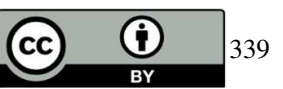




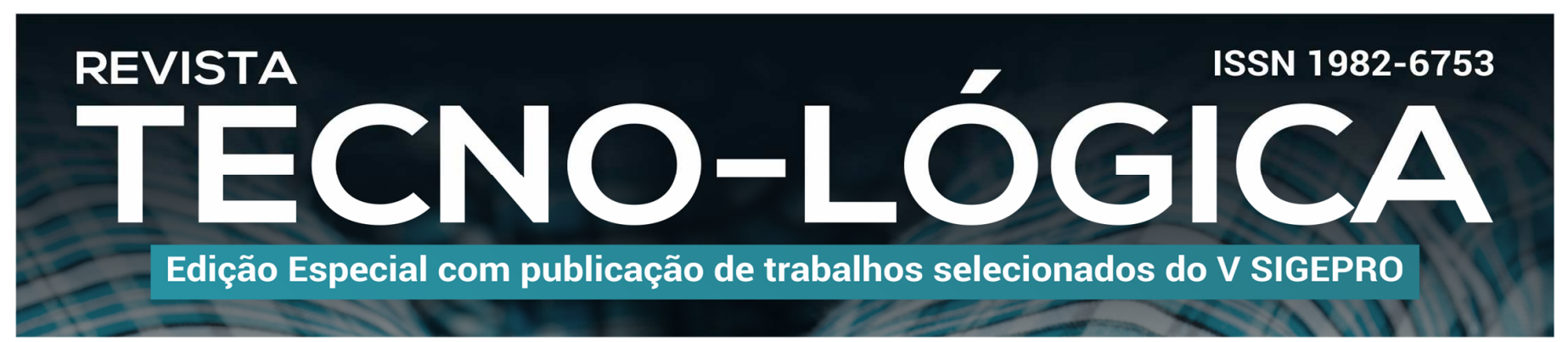

Centro de Triagem, 60 para a APAE (Associação de Pais e Amigos dos Excepcionais) e 430 para outras demandas solicitadas.
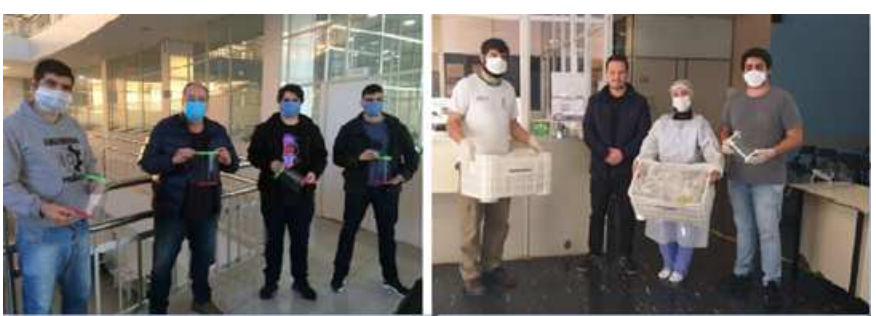

Figura 8 - Entrega das máscaras (Caçador online (2020) [8])

\section{Resultados}

O projeto de extensão produziu protetores faciais utilizando a impressão 3D. O modelo desenvolvido apresentou um baixo custo de produção, devido ao custo médio do filamento utilizado (ABS) girar em torno de $\mathrm{R} \$ 90,00 / \mathrm{Kg}$. Consumiu-se $37.71 \mathrm{~g}$ de material para fabricar um único protetor facial, o que totalizou um custo fixo de aproximadamente $\mathrm{R} \$ 3,39$ de filamento, sendo $R \$ 0,39$ para a parte inferior e $R \$ 3,00$ para a parte superior. O material utilizado na viseira foi a folha de acetato transparente que custou R $\$$, 80 /unidade resultando em um custo total de fabricação de R\$ 4,19/unidade. Afirma-se que a margem de contribuição seria alta se o intuito fosse o de vender as máscaras, e isso tornaria o modelo uma opção mais lucrativa para as companhias. Pela necessidade de recursos em qualquer processo de produção e devido ao projeto concentrar-se no auxílio a pandemia, torna-se fundamental a produção de um elevado número de faces shields num intervalo menor de tempo. Dessa forma, o tempo total para a impressão da máscara (parte superior e inferior), foi de 62 minutos, enquanto o modelo anterior (RC1), obteve um tempo de processamento de 156 minutos, ou seja, uma redução de $65 \%$ do tempo base. O tempo de produção e o custo variável mais baixos permitem que se atenda a uma alta demanda do modelo desenvolvido.
Tabela 2 - Tempo de produção dos modelos

\begin{tabular}{ccc}
\hline $\begin{array}{c}\text { Modelo (Parte } \\
\text { superior) }\end{array}$ & Quantidade (Kit) & $\begin{array}{c}\text { Tempo de } \\
\text { Processamento em } \\
\text { minutos }\end{array}$ \\
\hline RC1 & 2 & 156 \\
Atual & 2 & 62 \\
\hline
\end{tabular}

\section{Conclusão}

Diante da realização do projeto, conclui-se que a manufatura aditiva se consolidou como um processo de suma importância na indústria 4.0 para aplicações em múltiplas áreas, podendo desenvolver produtos com elevada tecnologia e inovação.

Desenvolver o projeto permitiu um melhor conhecimento a respeito dos processos de impressão $3 \mathrm{D}$, e os executores envolvidos no projeto foram beneficiados com uma experiência real na formação acadêmica. Por meio da prática dos conhecimentos adquiridos ao longo do curso, integrou-se os a uma demanda atual da comunidade, diante da escassez de utensílios hospitalares, sobretudo os EPIs, em consequência da pandemia do corona vírus.

Ao longo do desenvolvimento do projeto, foi exposto a elaboração e a produção das faces shields pela impressora 3D. Conforme as características de impressão, o modelo se mostrou com uma elevada economia de material e um custo produtivo reduzido. a qual permitiu uma evolução considerável no processo. Mediante ao feedback dos usuários, confirmou-se que as máscaras protetoras desenvolvidas exerceram sua função para as quais foram elaboradas.

O projeto de extensão proporcionou a aplicação de um dos tripés do ensino público federal, e tal proposta beneficia todos os segmentos envolvidos. Isso ocorre mediante a uma maior visibilidade perante o público externo como meio de disseminação 


\section{REVISTA}

r
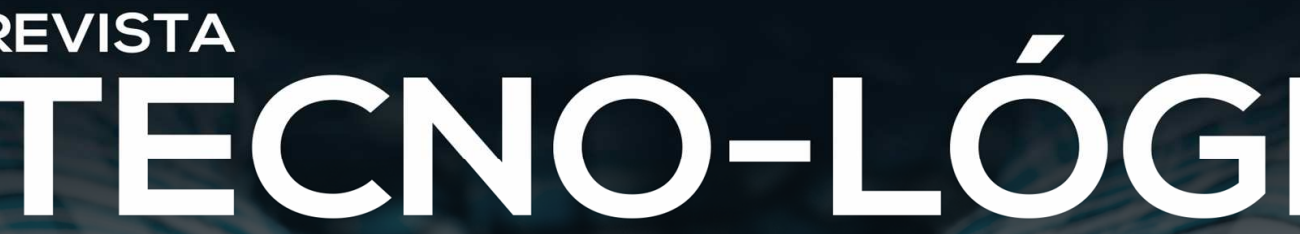

ISSN 1982-6753

Edição Especial com publicação de trabalhos selecionados do V SIGEPRO

de conhecimento e aplicação de atividades que visam contribuir com seu papel social na comunidade, obtendo, dessa forma, uma realização pessoal de estar cooperando na maior crise de saúde pública do século XXI.

\section{Agradecimentos}

Os autores gostariam de agradecer ao IFSC - Instituto Federal de Santa Catarina, que disponibilizou os laboratórios de processamento e todos os materiais para a realização do projeto.

\section{FACE SHIELDS PRODUCTION USING ADDITIVE MANUFACTURING: AN AID IN THE FIGHT AGAINST COVID-19}

ABSTRACT: Due to the epidemiological crisis faced by the Brazilian population, it is necessary to use IES (Higher Education Institutions), that might know how to assist in the fight against Covid-19. On account of its extension practices and its infrastructure and equipment available at the campus, the Federal Institute of Santa Catarina (IFSC) can offer medical essentials to the community to assist them. In this context, a project was developed using additive manufacturing to produce Face Shields. Considering this, the project employed 3D printing technology to design and manufacture face shields. An existing model on the market was used as a reference, and from that point on, some changes were made to optimize the process and reduce manufacturing costs. Therefore, the face shields produced were donated to health professionals in the city of Caçador-SC to assist them in the fight against Covid-19.

Keywords: Additive manufacturing. 3D printing. Product planning. Modeling.

\section{Referências}

[1] MONZÓN, M.D. et al. Standardization in additive manufacturing: activities carried out by international organizations and projects. International Journal of Advanced Manufacturing Technology, v. 76, n. 5-8, p. 1111-1121, 2014.

[2] BUMGARNER, B. Getting started with a 3D printer. Make. P. 12-16, 2003.

[3] CUNICO, M. W. M. Desenvolvimento de nova tecnologia da manufatura aditiva baseado em formação seletiva de compósito. Tese (Doutorado). Programa de Pós-Graduação em Engenharia Mecânica e Área de Concentração em Projeto Mecânico. São Carlos, 2013.

[4] GIBSON, I.; ROSEN, D. W.; STUCKER, B. Additive manufacturing technologies: rapid prototyping to direct Digital manufacturing. 1. ed. Nova York: Springer, 2009.

[5] MACDONALD, N.P. et al. Comparing microfluidic performance of threedimensional (3D) printing platforms. Analytical Chemistry, v. 89, n. 7, p. 3858$3866,2017$.

[6] RAJA, I. \& FERNANDES, V.J. Reverse engineering: an industrial perspective. London: Springer-Verlag, pp. 1-8, 2008.

[7] PRUSA PRINTERS. Prusa Face Shield. Disponível em: https://www.prusaprinters.org/prints/25857-prusa-face-shield. Acesso em: 20 mar. 2020 .

[8] CAÇADOR ONLINE. Maicé recebe protetores faciais produzidos por alunos do IFSC. Disponível em: https://www.cacador.net/noticias/geral/2020/04/09/epismaice-recebe-protetores-faciais-produzidos-por-alunos-do-ifsc-

47975?fbclid\%3DIwAR1fMdZAvOPPJwEOJ8cP0TpDF31xqrs26MqRznYfqYEi IaltWv3iKVfKz0k\&sa=D\&ust=1586559780842000\&usg=AFQjCNELv10y5MILXOF0E7HdYGIwaskRQ. Acesso em: 9 abr. 2020. 